Research Note

\title{
"On-the-go" NIT technology to assess protein and moisture during harvest of wheat breeding trials
}

\author{
Glen P. Fox*, Gary Bloustein, John Sheppard \\ Department of Employment, Economic Development \& Innovation, Queensland Primary Industries E Fisheries, PO Box 2282, Toowoomba, Qld 4350, Australia
}

\section{A R T I C L E I N F O}

\section{Article history:}

Received 16 March 2009

Received in revised form

9 October 2009

Accepted 20 October 2009

\section{Keywords:}

Breeding

Near infrared

Protein

Wheat

Near infrared reflectance (NIR) has been used routinely in plant breeding programs for quality testing over many years. The number of research papers describing the prediction of post-harvest quality from breeding trials for basic traits, such as protein and moisture, to more complex traits such as wheat flour yield or barley hot water extract, is extensive. These previous studies related to cereal breeding, have been reviewed recently (Osborne, 2006). In the relatively new field of "on-the-go" NIR applications, recent studies have demonstrated where NIR has moved from post-harvest analysis to real time harvest situations. Initially, research in assessing forage quality by in-line systems on forage harvesters showed excellent potential (Garcia and Cozzolino, 2006; Kormann and Auernhammer, 2002; Maertens et al., 2004a). However, limited studies have reported on the application of NIR technology in real time analysis of grain crops, although Williams (2003) described this as an emerging technology.

There are very few studies actually reporting 'on-the-go' NIR applications for plant breeding. Sinnaeve et al. (2004) was one of the early reports to suggest the use of on-header NIR for a wheat breeding program but only presented results on the instrumentation to be used, which included calibrating an NIR using predicted values from another NIR instrument. In maize breeding, Welle et al. (2005) reported only moisture from an 'on-the-go' application. While wheat protein has also been estimated in a commercial

Abbreviation: NIR, near infrared reflectance; NIT, near infrared transmittance.

* Corresponding author. Tel.: +61 74639 8830; fax: +61 746398800.

E-mail address: glen.fox@deedi.qld.gov.au (G.P. Fox). harvester (Long et al., 2008; Maertens et al., 2004b), to date, only one study has shown any application of NIR 'on-the-go' assessment for estimated traits in a breeding trial situation (Welle et al., 2007). These authors showed considerable success when a NIR system was mounted on a plot harvester for canola breeding trials, where moisture, protein, oil and glucosinolates were estimated. Paul et al. (2008) provided a brief review of on-header applications, although much of their focus was on forage. Some mention was given to grain application but not specifically in wheat breeding.

In this study, we investigated the application of "on-the-go" assessment of wheat protein and moisture under a breeding trial situation.

\section{1. "On-the-go" protein and moisture assessment}

The "on-the-go" system was adapted using an existing optic fibre near infrared transmission (NIT) system (Crop Scan 2000G) with built in protein and moisture calibrations (NIR Technologies Australia) as described by Clancy (2004). The wavelength range was $720-1100 \mathrm{~nm}$ at $2 \mathrm{~nm}$ intervals.

The harvested sample was presented to the NIT instrument as a static sample in the sample receival hopper prior to being bagged. The system was configured as follows; grain was blown from the cleaners to the external hopper where the grain filled a NIT rectangular sample cell. The base of the sample cell was attached to a motor and was controlled to move up and down inside the cell to either empty or fill the cell. The cell moved up and down in a continuous motion every $6 \mathrm{~s}$. The light source directed light into 
a detector on the opposite side of the cell. If no grain was present then only a reference reading was taken, however when grain was present then a normal scan and subsequent estimation was carried out. Fig. 1 shows the instrument mounted on the side of the hopper. Inside the cabin, an operator fills a bags after a set time which is based on the time for the harvester to move in and out of the plot abut before the next run into the adjacent plot.

The NIT instrument was trialled on a breeding trial at DPI\&F Gatton Research Station in 2003 and at DPI\&F Kingsthorpe Research Farm in 2004. The trials were advanced breeding trials, targeted for a premium hard wheat classification of equal to or greater than a protein content of $13.0 \%$ ( $11 \%$ moisture basis) as required by the Australian wheat industry. One hundred and twenty plots were harvested in a forward in, backward out, sequence from each season. During the $15 \mathrm{~s}$ period to harvest each plot and move into position to harvest the next plot, sufficient grain flowed into the hopper where two readings were taken. The data for each sample was averaged in Excel after the file was downloaded from the NIT unit.

\section{Post-harvest validation}

The "on-the-go" harvested samples were scanned in the Foss NIRSystems 6500 using WinISI software (V 1.5). The calibrations for protein and moisture were developed in-house for predicting quality traits within the wheat breeding program.

A paired $t$-test routine in the statistical package, Genstat ${ }^{\circledR}$, was applied to determine if the predicted values from each NIR instrument were statistically different. A correlation between the 'on-the-go' NIT data and laboratory estimated NIR data was also carried out using Genstat ${ }^{\circledR}$.

We believe this to be the first report, in peer reviewed literature, detailing the use of NIT technology to estimate wheat protein and moisture content during the harvesting of breeding plots. The NIT instrument was mounted onto the grain receival hopper of a Kingaroy Engineering Works plot harvester (Fig. 1). The operator remained inside the header cabin, bagging the sample after two readings from the NIT instrument had been collected.

\section{3. "On-the-go" protein and moisture}

The "on-the-go" predicted protein and moisture values had a high degree of matching with the post-harvest grain predictions.

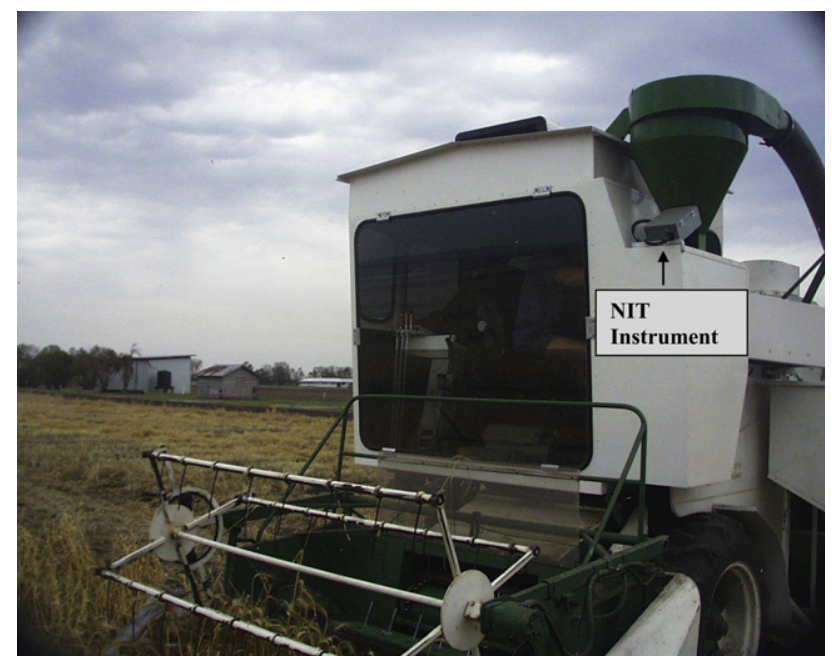

Fig. 1. NIT instrument mounted on the side of the grain collection hopper.
Table 1

Summary of header NIT and laboratory NIR values for protein and moisture, combined for 2003 and 2004 ( $n=120$ each season).

\begin{tabular}{|c|c|c|c|c|c|c|}
\hline & \multicolumn{3}{|c|}{ Header NIT values } & \multicolumn{3}{|c|}{ Laboratory NIR values } \\
\hline & $\begin{array}{l}\text { Range } \\
(\%)\end{array}$ & $\begin{array}{l}\text { Mean } \\
(\%)\end{array}$ & $\begin{array}{l}\text { SD } \\
(\%)\end{array}$ & $\begin{array}{l}\text { Range } \\
(\%)\end{array}$ & $\begin{array}{l}\text { Mean } \\
(\%)\end{array}$ & $\begin{array}{l}\text { SD } \\
(\%)\end{array}$ \\
\hline \multicolumn{7}{|c|}{ Averaged two seasons } \\
\hline Protein & $11.9-14.4$ & 12.9 & 0.4 & $12.1-14.2$ & 13.3 & 0.3 \\
\hline $\begin{array}{l}\text { Moisture } \\
2003\end{array}$ & $11.0-12.2$ & 11.6 & 0.2 & $11.4-12.6$ & 11.9 & 0.2 \\
\hline Protein & $12.0-14.2$ & 12.8 & 0.5 & $12.1-14.1$ & 13.3 & 0.4 \\
\hline $\begin{array}{l}\text { Moisture } \\
2004\end{array}$ & $11.0-12.1$ & 11.5 & 0.2 & $11.5-12.5$ & 11.8 & 0.2 \\
\hline Protein & $11.9-14.4$ & 12.9 & 0.4 & $12.2-14.2$ & 13.2 & 0.3 \\
\hline Moisture & $11.1-12.2$ & 11.6 & 0.2 & $11.6-12.6$ & 11.9 & 0.3 \\
\hline
\end{tabular}

The average for the combined season was $12.9 \%$ and $11.6 \%$ for protein and moisture respectively as estimated by the NIT system while for the laboratory NIR estimates the averages were $13.1 \%$ and $11.9 \%$ respectively for protein and moisture. Table 1 shows additional descriptive analysis of the protein and moisture data.

The range was quite broad for protein as can be expected in wheat breeding trials. The moisture content was more narrow but close to the desirable harvest moisture of $12.0 \%$. The laboratory NIR instrument has protein and moisture models built up over a number of years using samples specifically from the breeding program. Whereas, the commercial NIT system had built in calibration models for protein and moisture, supplied by the manufacturer, it could require updating with samples specifically from our trials to further improve the calibration.

The difference between total samples means between the header NIT and laboratory NIR were only $0.4 \%$ and $0.3 \%$ for protein and moisture, respectively. These values were not significantly different at the 95\% confidence level. Although, this was a small data set, the results indicated the system could be used to provide reliable protein and moisture values "on-the-go" at harvest. In addition, while the level of precision between the "on-the-go" and validated values may not be as high as desired, for early generation breeding trials, the ranking of lines against parent varieties or commercial check varieties is generally more important than absolute values.

There was a good correlation $(r=0.91)$ for protein between the 'on-the-go' system and the laboratory NIR system (Fig. 2) with reasonable agreement. There was a slight bias (0.13) with the laboratory NIR calibration estimating higher protein values. As mentioned previously, if this system was to become a routine application for our breeding program then samples from our program would have to be built into the commercial calibration

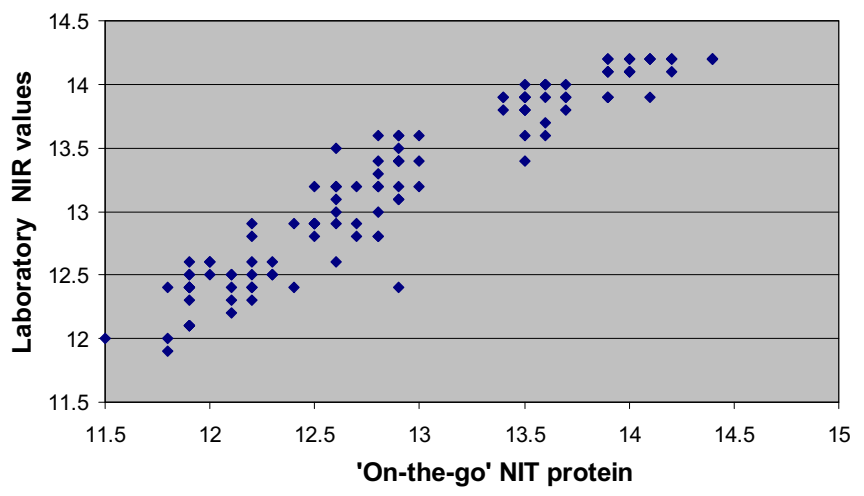

Fig. 2. Correlation between 'on-the-go' NIR and laboratory NIR protein values. 


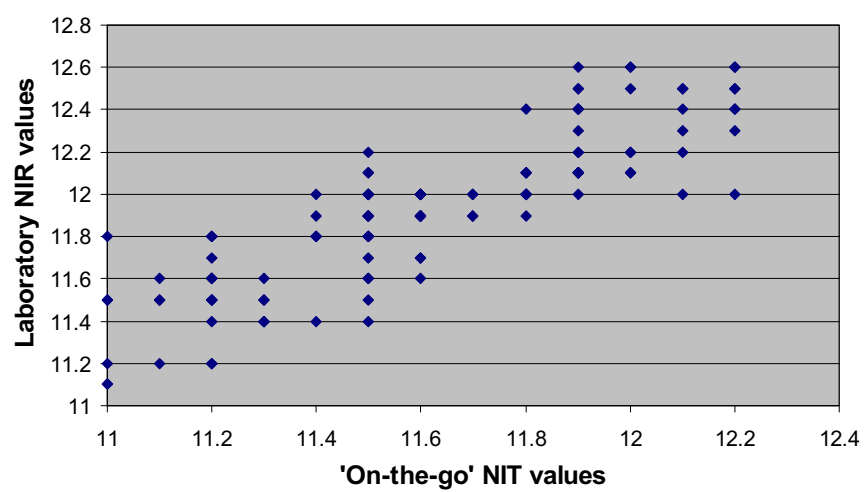

Fig. 3. Correlation between 'on-the-go' NIR and laboratory NIR moisture values .

model. Commercialisation constraints prevented us from performing an upgraded calibration between seasons. Fig. 2 shows the moisture correlation $(r=0.86)$ between the two instruments. There was an even lower correlation suggesting there was less agreement between the two calibrations. As for protein, there was a slight bias (0.16) with the laboratory NIR estimating slightly higher values. Further work would be required to incorporate breeding samples which for our program are usually harvested at around $12.0 \%$ moisture Fig. 3

The use of a broad range NIR technology for breeding programs appears to have three possible applications. First, aerial imaging could rapidly assess a breeding site for condition; i.e. within and between plots as well as possibly estimate yield or protein content for each plot. Second, aerial images can provide a pre-harvest indication of average site protein, allowing sites to be prioritised for harvesting. This would enable the harvest crews to improve their harvest risk-management by selectively harvesting trials and reducing the risk of pre-harvest rain damage. Also, the breeder could estimate protein on all samples from all breeding generations, allowing selection decisions to be made on the basis of grain quality and yield performance immediately post-harvest. Finally, as described in the study outlined here, reliable "on-the-go" technology could reduce the costs of post-harvest grain assessments, depending upon the number of calibration models for quality attributes built into the NIR/NIT system. Samples would be manually handled less often, and further processing may not be required if grain protein falls outside a predetermined level.

These results indicate the 'on-the-go' system was an excellent tool for having real time data at harvest for a wheat breeding program. However, there are a number of factors to be addressed prior to continuing and implementing this as a routine technology within the program. Firstly, further evaluation, using an increased number of sites and breeding plots, is planned to validate this preliminary study. Secondly, appropriate reference methods rather than other NIR instruments will be used to obtain accurate protein and moisture values for validation of the predicted values as well as for the samples built into the expanded calibrations. Thirdly, consideration must be given to field effects such as temperature at harvest as well as the quality of the sample going into the 'on-thego' system; for example chaff and other contamination. Fourthly, expansion of the calibration set to include additional quality traits (e.g. vitreousness, starch content) in the NIR unit could further enhance the breeding selection process; i.e. selection of lines to be progressed within the breeding program based on quality traits other than protein.

\section{Acknowledgements}

The authors wish to thank the Department of Primary Industries \& Fisheries and the Grains Research and Development Corporation for continued financial support.

\section{References}

Clancy, P.J., 2004, Spectral matching two different brands of NIR whole grain analysers. In: A.M.C. Davis, A. Garrido-Varo (Eds.), Proceedings of the 11th International Conference of Near Infrared Spectroscopy. Cordoba Spain 2003. NIR publications West Sussex United Kingdom, pp. 259-264.

Garcia, J., Cozzolino, D., 2006. Use of near infrared reflectance (NIR) spectroscopy to predict chemical composition of forages in broad-based calibration models. Agricultura Tecnica 66, 41-47.

Kormann, G., Auernhammer, H., 2002. Continuous moisture measurements in self-propelled forage harvesters. Landtechnik 57, 264-265.

Long, D.S., Engel, R.E., Siemens, M.C., 2008. Measuring grain protein concentration within-line near infrared reflectance spectroscopy. Agronomy Journal 100, 247-252.

Maertens, K., De Baerdemaeker, J., Reyns, P., 2004a. In-line quality measurements on forage maize. Proceedingsof the 7th International Conference on Precision Agriculture and other Precision Resources Management, Hyatt Regency, Minneapolis, MN, USA, 25-28 July, 2004, pp. 1168-1176.

Maertens, K., Reyns, P., De Baerdemaeker, J., 2004b. On-line measurement of grain quality with NIR technology. Transactions of the American Society of Agricultural Engineers 47, 1135-1140.

Osborne, B.G., 2006. Applications of near infrared spectroscopy in quality screening of early-generation material in cereal breeding programmes. Journal of Near Infrared Spectroscopy 14, 93-101.

Paul, C., Montes, J.M., Williams, P., 2008. Near infrared spectroscopy on agricultural harvesters: the background to commercial developments. NIR News 19, 8-11.

Sinnaeve, G., Herman, J.L., Baeten, V., Sadaoui, Y., Frankinet, M. Dardenne, P., 2004. Quality assessment of wheat and forage using diode array NIR instrument on the harvester. In: A.M.C. Davis, A. Garrido-Varo (Eds.), Proceedings of the 11th International Conference of Near Infrared Spectroscopy. Cordoba Spain 2003. NIR publications West Sussex United Kingdom, pp. 319-325.

Welle, R., Greten, W., Muller, T., Weber, G., Wehrmann, H., 2005. Application of near infrared spectroscopy on-combine in corn grain breeding. Journal of Near Infrared Spectroscopy 13, 69-75.

Welle, R., Zahle, K., Hildebrand, C., Kraling, K., Greten, W., 2007. Application of near infrared spectroscopy on-combine for canola breeding. Journal of Near Infrared Spectroscopy 15, 317-325. 